\title{
Proton catalysis with active carbons and partially pyrolyzed carbonaceous materials
}

\author{
V. V. Strelko*, S. S. Stavitskaya, Yu. I. Gorlov \\ Institute for Sorption and Problems of Endoecology of NAS of Ukraine, 13 General Naumov St., 03164, Kyiv, Ukraine
}

\section{A R T I C L E I N F O}

Article history:

Received 15 May 2014

Accepted 19 May 2014

Published 20 June 2014

\section{Keywords:}

Active carbon

Oxidized carbon

Solid acid catalyst

Quantum chemical calculation

Sulfonated carbonaceous material

Phosphorylated carbon

Partially pyrolised organic compound

Catalytic conversion biobased raw

material

\begin{abstract}
A B S T R A C T
The development of environmentally friendly solid acid catalysts is a priority task. Highly oxidized activated carbon and their ion-substituted (saline) forms are effective proton transfer catalysts in esterification, hydrolysis, and dehydration, and thus are promising candidates as solid acid catalysts. Computations by the ab initio method indicated the cause for the enchanced acidity of the carboxylic groups attached to the surface of highly oxidized carbon. The synthesis of phosphorilated carbon was considered, and the proton transfer reactions catalyzed by them in recent studies were analyzed. The development of an amorphous carbon acid catalyst comprising polycyclic carbonaceous (graphene) sheets with $-\mathrm{SO}_{3} \mathrm{H},-\mathrm{COOH}$ and phenolic type $\mathrm{OH}$-groups was carried out. These new catalysts were synthesized by partial pyrolysis and subsequent sulfonation of carbohydrates, polymers, and other organic compounds. Their high catalytic activities in proton
\end{abstract} transfere reactions including the processing of bio-based raw materials was demonsrated.

(C) 2014, Dalian Institute of Chemical Physics, Chinese Academy of Sciences. Published by Elsevier B.V. All rights reserved.

\section{Introduction}

About a hundred years ago already, publications have appeared about the ability of activated carbon to accelerate electron transfer reactions, namely the oxidation of alcohols, olefins, sulfur dioxide in the gaseous phase, and others, as well as by oxalic and uric acids in aqueous solutions. Since then, interest in this phenomenon has increased, which is reflected in numerous articles with experimental and theoretical data and also in a number of fundamental reviews and specialized monographs [1-6].

However, these publications only partially covered the participation of activated carbon in acid-base catalytic reactions, in particular, the process of proton transfer, although there are reasons for comprehensive studies on activated carbon as a recyclable solid acid material. It is common knowledge that the attack on carbon by strong oxidants leads to the grafting of carboxylic and phenolic groups onto the surface with plentiful mobile protons, which is a good reason to assign them to the category of highly porous solid acids. The oxidation of carbon is not the only way of introducing grafted acid groups onto their surface. Protonated surface functionalization can also be achieved by the phosphorylation of active carbon and other carbonaceous materials in the case of their heat treatment with phosphoric acid [7-10] or by the sulfonation with concentrated sulfuric acid (sulphonated carbon) [11-17].

In recent years, it has also been shown that the sulfonation of incompletely carbonized cellulose, starch, glucose and some polymers makes it possible to get hard carbon-based insoluble solid acids, which can potentially be uses as a replacement for

* Corresponding author. E-mail: ispe@ispe.kiev.ua

DOI: 10.1016/S1872-2067(14)60147-9 | http://www.sciencedirect.com/science/journal/18722067 | Chin. J. Catal., Vol. 35, No. 6, June 2014 
the homogenous sulphuric acid catalyst [11-17]. Meanwhile, mainly for historical reasons, oxidized, sulphonated, and phosphorylated carbon were studied mainly as cation exchangers with high selectivity towards multiply charged cations [18]. Only in recent years have they been studied for catalysis. The study of their catalytic activity in proton transfer reactions has been developed in the Ukraine since the 1960s by D. N. Strazhesko and I. A. Tarkovskaya and their colleagues, which was thereafter developed in the Institute for Sorption and Problems of Endoecology of the National Academy of Sciences of Ukraine with the participation of the authors of this article [18-22]. Somewhat later, these studies were also developed in papers [23-27] on the catalytic dehydration of alcohols.

From the viewpoint of modern trends concerning "green" approaches to acid-catalyzed chemical processes, the use of recyclable solid acid materials to replace the typically homogeneous acid catalyzed conditions has been recently promoted [28]. In fact, homogeneous catalysts $\left(\mathrm{HCl}, \mathrm{H}_{2} \mathrm{SO}_{4}\right)$ are difficult to separate from the reaction system, ecologically unfriendly, and cause equipment corrosion. On this view, many articles [11-17] have found that carbonaceous materials specifically modified by protonic groups are the best candidates among solid acids for various acid catalyzed reactions.

Unfortunately, the vast majority of publications on oxidized carbon that are dedicated to their catalytic properties are sketchy. Furthermore, they did not optimize the acidity of the surface functional groups of the oxidized carbon and evaluate the efficiency of these solid acids in various proton-transfer reactions. Therefore, this review will provide data covering the influence of various factors on proton mobility in the surface functional groups of activated carbon, as well as on their catalytic activity in the liquid phase and gas phase reactions of etherification, hydrolysis transesterification (biodiesel), dehydration, etc. In addition, we plan to analyze the studies dedicated to solid acid catalysts based on sulphonated and phosphonated carbon, and also different types of partly pyrolyzed carbonaceous materials.

\section{Acidity of the surface functional groups of oxidized carbon}

Incredible as it may seem, many publications dedicated to oxidized carbon in general have analyzed only the ratio of the total number of carboxylic and phenolic groups that determined the cation exchange (sorption) function of these carbon materials. Boehm titration with varying strength bases that are used for these analytical evaluations allows the reliably estimation of, for example, the ratio between these groups depending on the origin and oxidation conditions of the activated carbon. However, there were no thorough studies that evaluated the effect of carbon oxidation on the acidity of the functional groups. Meanwhile, it was assumed that the accumulation of electronegative - $\mathrm{COOH}$ groups on the surface layer of the carbon will increase the mobility of their protons. Nevertheless, the transmission of electrons in the condensed $\pi$-systems of carbonaceous material should be highly effective. A spectacular example of this effect can be seen in the data on benzoic and $o$-phtalic acids containing, respectively, one and two carboxy groups associated with phenyl ring. Due to the electronic effect, the acidity of $-\mathrm{COOH}$ groups of $o$-phtalic acid is one order of magnitude higher than benzoic acid ( $\mathrm{p} K_{\mathrm{a}} 3.2$ and 4.2 respectively). In oxidized carbon with a vast $\pi$-conjugation system, these effects should be present to a larger extent.

By taking into account all these conceptual aspects, in [29] we for the first time conducted a comprehensive study of the oxidation degree effect under atmospheric oxygen and nitric acid conditions on the structure and acidity of the surface functional groups of the carbonaceous materials. However, before proceeding to the presentation of these results, we shall first discuss the calculation methods of the ionization constants ( $\mathrm{p} K_{\mathrm{a}}$ values) of oxidized carbon and other carbonaceous materials with surface protonic groups.

\section{1. $p K_{a}$ of carbon oxidized to varying degrees}

The same approaches that are traditionally used for the ionization constant determination of polymeric acids, namely, ion exchange resins, are also applicable for the quantitative evaluation of the acidity of the surface functional groups of carbon. Usually even for monofunctional cation exchangers, the ionization constant $K_{d}$ varies continuously with the neutralization degree, which can be experimentally estimated from the shapes of the potentiometric titration curve of the polymeric acid by an alkali. According to ref. [30], the ionization constant of the polymeric acid (cation exchanger) is calculated from the equation

$$
K_{\mathrm{d}}=\frac{\left[H^{+}\right] \cdot\left[A^{-}\right]}{[H A]} \cdot f(z)
$$

where $\left[\mathrm{A}^{-}\right]$and $[\mathrm{HA}]$ are the content of ionized and non-ionized protonic groups in the ion exchanger, and $z$ is the ratio of their content in the matrix. After a transformation to $\mathrm{p} K_{\mathrm{a}}\left(\mathrm{p} K_{\mathrm{a}}=-\log \right.$ $K \mathrm{~d}$ ), we use the Henderson-Hasselbach equation:

$$
\begin{gathered}
\mathrm{p} K_{\mathrm{a}}=\mathrm{pH}-n \log \frac{1-\alpha}{\alpha} \\
\mathrm{p} K_{\mathrm{a}}=\mathrm{pH}
\end{gathered}
$$

where $\alpha$ is the neutralization degree of the ion exchanger functional groups.

This equation gives the most reasonable results for neutralization degree values with $\alpha=0.5$. In this case, the equilibrium $\mathrm{pH}$ of the solution (for potentiometric titration) is approximately equal to the $\mathrm{p} K_{\mathrm{a}}$ value of the corresponding functional groups. In the case of multifunctional cation exchangers, to which oxidized carbon are also related, the $\mathrm{p} K$ a values for some functional groups types can be obtained from the $\mathrm{pH}$ values because of the corresponding bend of the titration curves (extrema) for the same values of $\alpha=0.5$. Using this approach, the author of [18] concluded that the values of the ionization constants $K_{\mathrm{d}}$ of oxidized carbon lay in the range from $10^{-2}$ to $10^{-10}$ (i.e., $\mathrm{p} K_{\mathrm{a}}=2-10$ ). In the later studies for this purpose, the method used differential potentiometry [31].

In ref. [29], we investigated how the type of functional groups and their $\mathrm{p} K_{\mathrm{a}}$ values depend on the degree of oxidation 
Table 1

Amount of functional groups on the carbon KAU surface oxidized to varying degrees by atmospheric oxygen and concentrated $\mathrm{HNO}_{3}$.

\begin{tabular}{|c|c|c|c|c|c|}
\hline \multirow{2}{*}{ Oxidized carbon KAU } & \multirow{2}{*}{ Oxidation time, $\mathrm{h}$} & \multirow{2}{*}{ 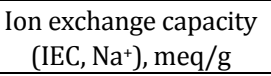 } & \multicolumn{3}{|c|}{ Amount of acid groups, meq/g } \\
\hline & & & Strong acidic carboxylic group & Week acidic carboxylic group & Phenolic group \\
\hline Oxidized by air & 2 & 1.0 & 0.2 & 0.2 & 0.6 \\
\hline \multirow[t]{3}{*}{ at $410^{\circ} \mathrm{C}$} & 6 & 1.7 & 0.6 & 0.2 & 0.9 \\
\hline & 9 & 1.9 & 0.8 & 0.3 & 0.8 \\
\hline & 20 & 2.4 & 1.1 & 0.3 & 1.1 \\
\hline Oxidized by boiling & 2 & 1.5 & 0.8 & 0.2 & 0.5 \\
\hline \multirow[t]{3}{*}{$20 \% \mathrm{HNO}_{3}$} & 5 & 1.9 & 1.0 & 0.4 & 0.5 \\
\hline & 10 & 2.2 & 1.6 & 0.2 & 0.4 \\
\hline & 15 & 2.7 & 1.4 & 0.6 & 0.7 \\
\hline
\end{tabular}

* Porous structure characteristics of the initial carbon KAU: $S_{\mathrm{sp} .}=1100 \mathrm{~m}^{2} / \mathrm{g}, R_{\mathrm{mes}}$ opore $=10-30 \mathrm{~nm}$.

of the carbon surface. The quantitative determination of the different types of functional groups were carried by the Boehm method, i.e., by titrating with $\mathrm{NaHCO}_{3}, \mathrm{Na}_{2} \mathrm{CO}_{3}, \mathrm{NaOH}$, and $\mathrm{C}_{2} \mathrm{H}_{5} \mathrm{ONa}$ solutions. The activated carbon $\mathrm{KAU}$, prepared from apricot stones, and synthetic carbon SCN, obtained from a polyvinylpyridine copolymer [32,33], were used in the investigation. These samples when oxidized to varying degrees gave the potentiometric titration curves in $0.1 \mathrm{~N} \mathrm{NaOH}$ solution with a background of $0.1 \mathrm{~N} \mathrm{NaCl}$ using the different amounts of sample. In this case, the oxidation degree of the carbon was also estimated from the value of the ion exchange capacity (IEC), determined from the titration curves in $\mathrm{mg}$ eqv of $\mathrm{Na}^{+}$ions at $\mathrm{pH}=11$.

The data is summarized in Table 1 and Fig. 1. As Table 1 shows, at low oxidation degree, weak acidic phenolic groups are predominantly formed in the surface layer. Increasing the oxidation degree caused the increase in the amount of strong and weak carboxylic groups.

Figure 1 provides information on the initial run of the potentiometric titration curves of synthetic carbon SCN that was oxidized to varying degrees with nitric acid. The curves are plotted as the cation exchange capacity for $\mathrm{H}^{+}\left(\mathrm{Na}^{+}\right)$ions versus equilibrium $\mathrm{pH}$ value. At low oxidation degrees (IEC $=1.2$ $\mathrm{meq} / \mathrm{g}$ ) ion exchange sorption commences at a relatively high $\mathrm{pH}(\sim 6)$. This means that at low oxidation degrees, weak acidic

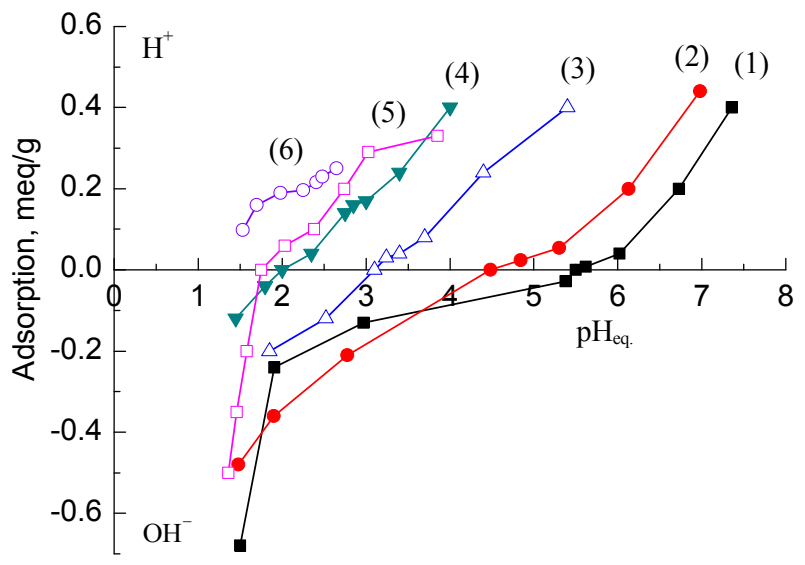

Fig. 1. Potentiometric titration curves of SCN synthetic carbon which differ in their oxidation degree (1.2-3.0 meq/g) after oxidation by nitric acid. (1) 1.2; (2) 1.3; (3) 1.8; (4) 2.4; (5) 2.8; (6) 3.0 meq/g [29]. groups are formed in the carbon surface layer. The increasing of the oxidation degree shifted the beginning of ion exchange sorption to the more acidic region. Finally, at the highest oxidation degree (IEC = $3 \mathrm{meq} / \mathrm{g}$ ), the ion exchange sorption of cations began in a very acidic range $(\mathrm{pH} \approx 1.2-1.3)$. Similar titration curves were obtained also for carbon KAU oxidized by air or nitric acid.

In the above description, the main interest is in how the dissociation constant $K_{\mathrm{d}}\left(\mathrm{p} K_{\mathrm{a}}\right)$ of the surface functional groups depended on the oxidation degree of the carbon surface. Figure 2 shows the dependence of the $\mathrm{p} K_{\mathrm{a}}$ values (for two types of carbon) as a function of the oxidation degree (IEC). For all the carbon samples, $\mathrm{p} K_{\mathrm{a}}$ tended towards a value of $\sim 1.2-1.3$ at the maximum oxidation degree, which was where there was the maximum possible number of acid surface groups. In other words, highly oxidized active carbons are hard solid acids with acidic properties that approach those of sulphocationites.

\subsection{Quantum chemical estimation of the deprotonation energy of carboxylic groups}

Quantum chemical studies were conducted for evaluating the influence of the number of functional groups on oxidized carbon (i.e., effect of oxidation degree) on proton mobility. The studies consisted of investigations of the changes in deprotonation energy of each new (additional) carboxylic group intro-

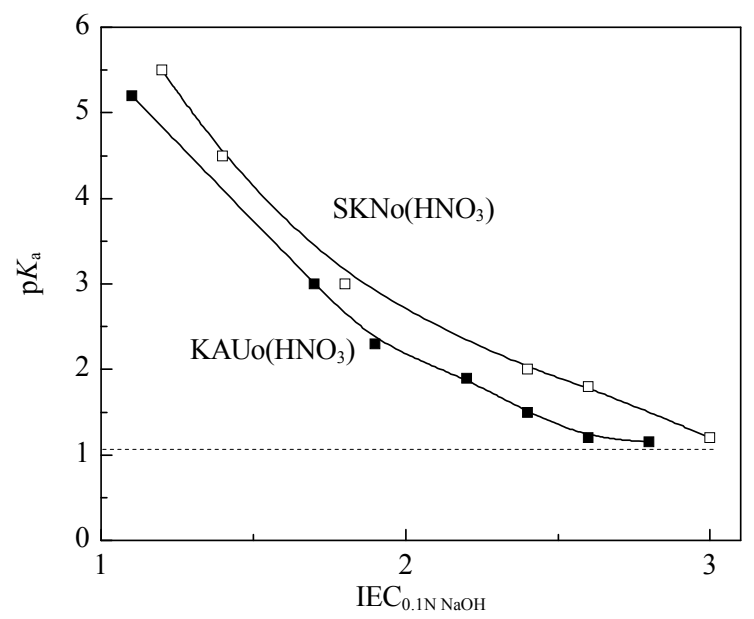

Fig. 2. $\mathrm{p} K_{\mathrm{a}}$ values of the surface groups as a function of oxidation degree of the carbon at the initial stage of its neutralization with alkali [29]. 
duced into carbon cluster models with had seven and sixteen condensed rings (including clusters with phenolic groups). Similar calculation approaches were used as those cited earlier in $[33,34]$. The following clusters were investigated: $\mathrm{C}_{24} \mathrm{H}_{12-n}(\mathrm{COOH})_{n}, \quad \mathrm{C}_{48} \mathrm{H}_{16-n}(\mathrm{COOH})_{n}, \quad \mathrm{C}_{48} \mathrm{H}_{12-n}(\mathrm{OH})_{4}(\mathrm{COOH})_{n}$, where $n=1-6$ (Table 2, the calculations used clusters not only with carboxyl but also phenolic groups). In contrast to [33,34], $a b$ initio calculations were performed using density functional theory with the exchange-correlation functional B3LYP [35] in the split-valence basis $6-31 \mathrm{G}(\mathrm{d})$ that take into account the $\mathrm{d}$ orbitals of the carbon and oxygen atoms and with full geometry optimization of the clusters. The calculated data of the deprotonation energy for each new carboxylic group, which was linked to the $\pi$-conjugated systems consisting of seven and sixteen condensed rings are presented in Table 2.

The data in Table 2 clearly indicated that the deprotonation energy $\Delta E\left(\mathrm{H}^{+}\right)$of the $\mathrm{COOH}$ groups decreased gradually due to the their accumulation in the clusters. This means that the acidity of these groups increased ( $\mathrm{p} K_{\mathrm{a}}$ value decreased). Moreover, it is interesting that in case of the larger carbon clusters $\left(\mathrm{C}_{48}\right)$ the absolute $\Delta E\left(\mathrm{H}^{+}\right)$values were lower than the smaller clusters $\left(\mathrm{C}_{24}\right)$. This was obviously due to the increase of the $2 \pi$ electron delocalization area of the oxygen in the carboxylic groups associated with clusters consisting of 16 condensed rings, which caused a reduction in the electron density on the oxygen atoms of protonic groups in comparison with clusters C24.

Finally, in clusters containing four phenolic groups in addition to the carboxylic groups, the decreasing effect of $\Delta E\left(\mathrm{H}^{+}\right)$ was the most pronounced. This result is very interesting because these clusters most fully imitate the oxidized carbon, since they contained both carboxyl and phenolic groups. The nature of a deeper electronic impact due to the protonic ability of the $\mathrm{COOH}$ groups in this case is not clear yet.

Thus, $a b$ initio computations have convincingly demonstrated the increase of proton mobility (increase of acidity) of the carboxylic functional groups (carboxylic functionality) due to their accumulation in the clusters. The curve shape of the $\Delta E\left(\mathrm{H}^{+}\right)$dependency on the ring number for $\mathrm{C}_{48}$ clusters containing four phenolic groups (Fig. 3) is also curious. In the case of three ring clusters with three carboxylic groups, an abrupt increase occurred in their acidity, which is in agreement with the experimentally established (Table 1) availability of weak and strong acidic carboxylic groups in carbon. The curve shape in Fig. 3 generally correlated with the curve shape in Fig. 2, and reflected the experimentally determined dependency of pKa of oxidized carbon on their oxidation degree. That is, the curves in

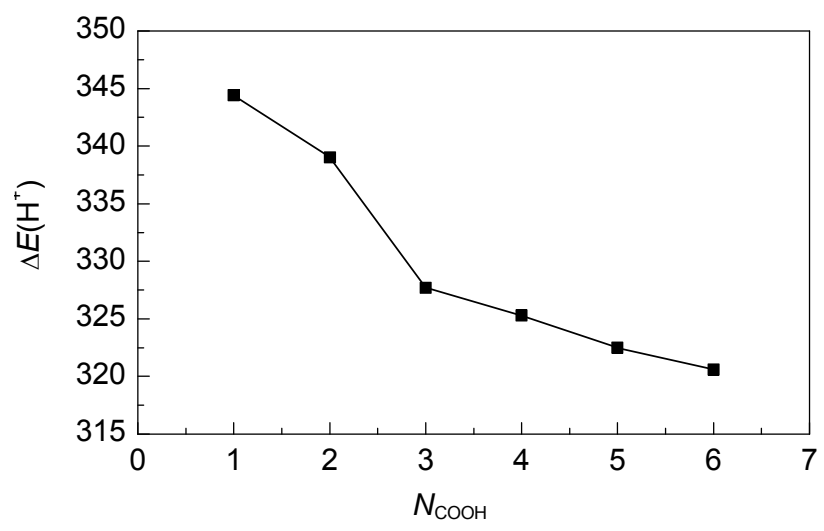

Fig. 3. Calculated changes of the deprotonation energy $\Delta E\left(\mathrm{H}^{+}\right)$as a function of the quantity of the carboxylic groups $N_{\mathrm{coOH}}$ on the clusters $\mathrm{C}_{48} \mathrm{H}_{12-n}(\mathrm{OH})_{4}(\mathrm{COOH})_{n}$.

Figs. 2 and 3 showed more acidity of the carbon with high oxidation degrees, which was also confirmed by the data in Fig. 1.

\subsection{Features of catalytic action of oxidized carbon in proton transfer reactions}

The surface of carbon oxidized with an oxidants has weakly acidic phenolic groups and highly acidic carboxylic groups. The data given in the previous section showed that the proton mobility of the most acidic carboxylic groups in the case of highly oxidized carbon was characterized by values of $\mathrm{p} K_{\mathrm{a}}=1.2-1.5$. For the same groups of carboxylic resins, $\mathrm{p} K_{\mathrm{a}}=3.5-4$. In other words, the carboxylic groups grafted to the surface of oxidized carbon are 2-3 orders more acidic than the same carboxylic groups associated with the alkyl polymer chains of carboxylic resins. This is precisely why the catalytic activity of oxidized carbon in proton transfer reactions are approximately the same as strongly acidic sulphocationites.

This explains why carboxyl cation exchangers do not catalyze the reactions accelerated by strong acids in solutions ( $\mathrm{H}^{+-}$-ions). At the same time, oxidized carbon catalyze proton transfer reactions not only in solutions but also in a gas phase, which has been experimentally established in many old papers [18]. Thus, the reactions accelerated by oxidized carbon were studied in detail [18-27], namely, ester formation and hydrolysis in solution and in the gas phase, dehydration of alcohols in the vapour phase, pinacolin rearrangement, hydrolysis of fats, reesterification of nutritive oils and fats and their mixtures [36], inversion (hydrolysis) of sucrose and maltose [37], etc. For instance, in the synthesis reaction of butyl acetate, [18-20]

Table 2

Deprotonation energy of newly introduced carboxylic groups in the cluster models of oxidized carbon, kcal/mol.

\begin{tabular}{|c|c|c|c|}
\hline \multirow{2}{*}{$\begin{array}{l}\text { Amount of introduced }-\mathrm{COOH} \\
\text { groups in clusters, } N\end{array}$} & \multicolumn{3}{|c|}{ Formula of cluster model and deprotonation energy of - $\mathrm{COOH}$ groups $\Delta E\left(\mathrm{H}^{+}\right), \mathrm{kcal} / \mathrm{mol}$} \\
\hline & $\mathrm{C}_{24} \mathrm{H}_{12-n}(\mathrm{COOH})_{n}$ & $\mathrm{C}_{48} \mathrm{H}_{16-n}(\mathrm{COOH})_{n}$ & $\mathrm{C}_{48} \mathrm{H}_{12-n}(\mathrm{OH})_{4}(\mathrm{COOH})_{n}$ \\
\hline 1 & 346.7 & 343.2 & 344.4 \\
\hline 2 & 345.6 & 340.2 & 339.0 \\
\hline 3 & 343.4 & 335.1 & 327.7 \\
\hline 4 & 340.8 & 335.4 & 325.3 \\
\hline 5 & 337.9 & 332.8 & 322.5 \\
\hline 6 & 336.3 & - & 320.6 \\
\hline
\end{tabular}


showed that with increasing total protonic surface groups (i.e. with increasing oxidation of the carbon) the catalytic activity increased. The catalytic activity also increased exponentially with temperature (Fig. 4). After some initial fall in the activity of a carbon catalyst, there is a long term stable state, where its productivity is almost unchanged. It has been found [20] that under stable state catalysis, there is a first order reaction both for the acid and alcohol, which is only slightly inhibited by the reaction products (ester and water). Finally, it has been also established that the specific productivity of a carbon catalyst $\left(\mathrm{W}, \mathrm{mol} \cdot \mathrm{sec}^{-1} \cdot \mathrm{m}^{2}\right.$ of catalyst) can be described by

$$
W=\frac{K \cdot C_{1} \cdot C_{2}}{1+a C_{3} \cdot b C_{4}}
$$

where $K$ is the reaction rate constant; $\mathrm{C}_{1}, \mathrm{C}_{2}, \mathrm{C}_{3}$, and $\mathrm{C}_{4}$ are equilibrium concentrations of acetic acid, butanol, acetic butyl ester, and water, respectively; $a$ and $b$ are ether and water adsorption coefficients.

The calculated activation energy for a heterogeneous process catalyzed by an oxidized carbon was 8-9 kcal/mol. For a homogeneous process catalyzed by $\mathrm{HCl}$, this value was significantly higher (14-16 kcal/mol) [18].

The important aspect here is that the features of catalytic action of oxidized carbon are interesting not only for the development of new technologies for renewable bio-resources (cellulose, sacchars), but also for medicine. The therapeutic effects of medical carbon (hemo- and oral sorbents) were associated only with their absorption properties [6]. However, we [38] developed ideas that in contact with biological fluids, carbon can also show catalytic activity (similar to enzymes) and act as catalysts in oxidation reactions of harmful and toxic substances (e.g. creatinine, uric acid), or have the ability to catalytically decompose lipid peroxides and also neutralize reactive

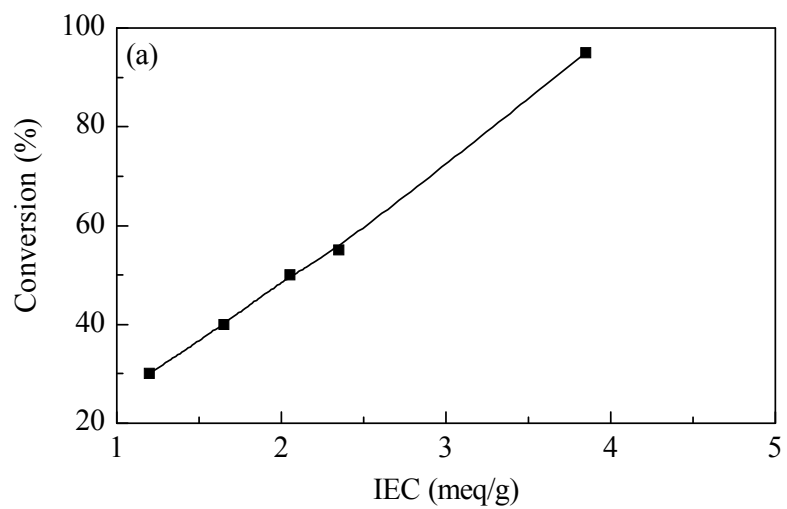

oxygen species and first of all the superoxide and hydroxylic radicals. Oxidized carbon to some extent show properties of hydrolase and lipase type enzymes, and can catalytically break up fats and carbohydrates [36,37]. Refs. [36,37] showed the possibility of the catalytic hydrolysis of fats, and hydrolysis of sucrose and maltose disaccharides to glucose. The processes were quite effective in regimes close to the conditions in organisms.

Table 3 presents data on the rate constants and activation energies for saccharose and maltose hydrolysis on conventional and oxidized active carbon SCN and KAU, produced from vinylpyridine copolymer and apricot stones, respectively $[32,39]$. The hydrolysis processes were carried out at temperatures close to body temperature for $2 \mathrm{~d}$, which corresponded to the passage time of oral sorbents through the stomach and intestines.

The data indicated that due to the high proton mobility from carboxylic groups attached to the carbon matrix, oxidized carbon showed high activity in proton transfer reactions comparable with the catalytic activity of sulphocationites. Information on the catalytic properties of oxidized coal and their metal-substituted forms were presented also in the monograph [34]. An interesting feature of oxidized carbon is the fact that their cation-substituted forms also have very high catalytic activity in the reactions of esterification, hydrolysis of ethers, disaccharides, fats, etc.

In the simplest case, (ion $\mathrm{Na}^{+}$) ion substitution of $\mathrm{H}^{+}$by $\mathrm{Na}^{+}$ ions in the surface layer can be represented by the scheme:
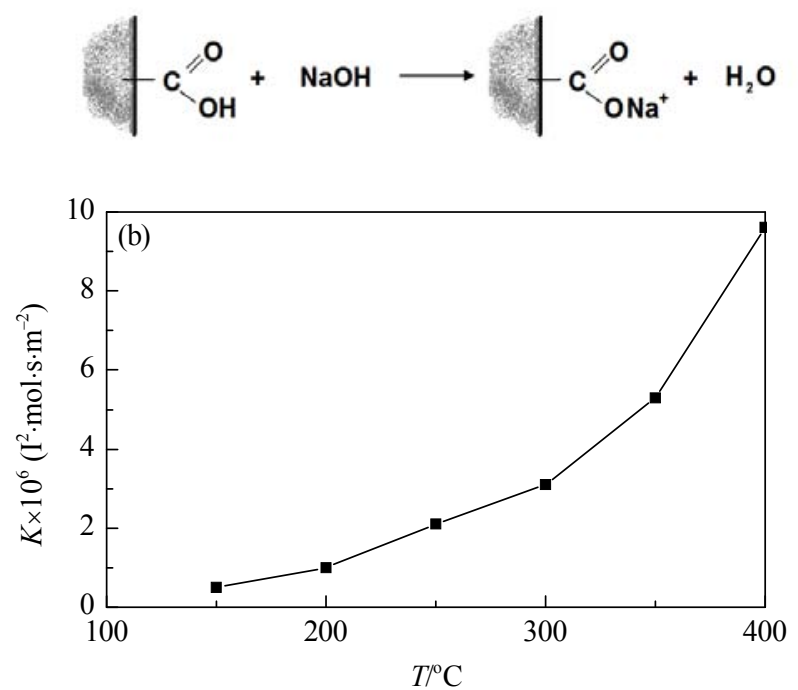

Fig. 4. Efficiency of the catalytic esterification of acetic acid with butanol in the presence of oxidized carbon ( $\mathrm{H}^{+}-$modification) as a function of oxidation degree (a) and temperature (b) $[18,20]$.

Table 3

Rate constants $\left(K_{\mathrm{r}}\right)$ and activation energies $(E)$ for saccharose and malthose hydrolysis on conventional (SCN, KAU) and oxidized (SCNo, KAUo) carbon sorbents.

\begin{tabular}{|c|c|c|c|c|c|c|c|c|c|}
\hline \multirow{3}{*}{ Sample } & \multirow{3}{*}{$\begin{array}{l}\text { Content of surface functional } \\
\text { groups, meq/g }\end{array}$} & \multicolumn{6}{|c|}{$K_{\mathrm{r}} \cdot 10^{7}, \mathrm{~s}^{-1}$} & \multicolumn{2}{|c|}{$E, \mathrm{~kJ} / \mathrm{mol}$} \\
\hline & & \multicolumn{3}{|c|}{ Saccharose } & \multicolumn{3}{|c|}{ Maltose } & \multirow{2}{*}{ Saccharose } & \multirow{2}{*}{ Maltose } \\
\hline & & $303 \mathrm{~K}$ & $313 \mathrm{~K}$ & $323 \mathrm{~K}$ & $303 \mathrm{~K}$ & $313 \mathrm{~K}$ & $323 \mathrm{~K}$ & & \\
\hline $\mathrm{SCN}$ & 0.72 & 0.23 & 0.93 & 1.40 & 0.14 & 1.40 & 2.30 & 73 & 113 \\
\hline SCNo & 2.60 & 4.30 & 17.40 & 28.00 & 8.60 & 13.40 & 25.60 & 52 & 59 \\
\hline KAU & 0.45 & 0.10 & 0.65 & 0.93 & 0.12 & 1.20 & 2.00 & 92 & 102 \\
\hline KAUo & 2.00 & 10.90 & 16.20 & 31.00 & 8.10 & 12.60 & 21.30 & 52 & 11 \\
\hline
\end{tabular}


The catalytic activity depends on the type of ion exchange sorbed cation and varies for different reactions. For the vapor phase synthesis of butyl acetate, the sequence of cations by their catalytic activity was [18]:

$$
\mathrm{Zn}^{2+}>\mathrm{Ba}^{2+}>\mathrm{Ca}^{2+}>\mathrm{Na}^{+}
$$

For comparison, the activity of the hydrogen and salt forms in Fig. 5 are shown as an example of $\mathrm{H}^{+}$and $\mathrm{Ba}^{2+}$ productivity versus time for butyl acetate synthesis.

\section{Proton catalysis on sulphonated carbon and partially pyrolyzed carbonaceous materials}

The treatment of mineral brown carbon with 2 to 3-fold excess of fuming sulfuric acid (oleum) leads to the chemical bonding of sulfonic-groups with the carbon matrix. As a result, a strongly acidic sulfonic cation exchanger, which is used in water treatment, that is similar in properties with the cation exchangers Amberlyst-15 and other types, is formed. This has drawn attention to the possibility of obtaining solid catalysts for proton transfer through the sulfonation of incomplete pyrolysis products of organic compounds $[7,11,17,40]$. Concerning carbon, there were only separate reports about the possibility of their partial sulfonation, and even then only under extreme conditions [11-14].

Work on solid acids based on partially pyrolyzed organic compounds treated by sulfuric acid should mentioned first the studies in $[11,12]$. In one of the first works in this field, the authors [11] showed that carbon-based solid acids can be synthesized from various polycyclic aromatic hydrocarbon such as naphthalene, anthracene, perylene and coronene by heating in sulfuric acid at 473-573 K. The resulting sulphonated aromatic compounds were incompletely carbonized, which resulted in the formation of a solid with a nominal sample composition of $\mathrm{CH}_{0.35} \mathrm{O}_{0.35} \mathrm{~S}_{0,14}$. These solid acids contain relatively high densities of acidic groups (predominantly $-\mathrm{SO}_{3} \mathrm{H}$ groups) $\sim 4.9$

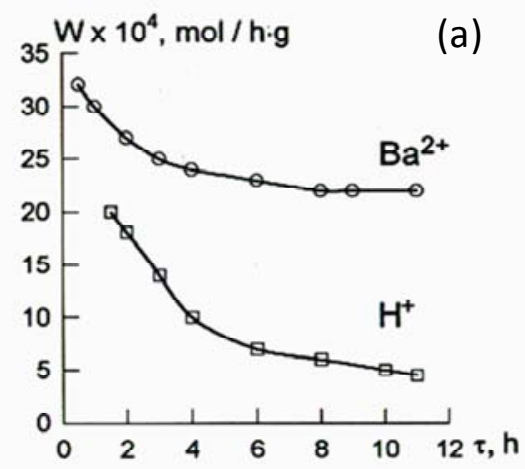

(b)

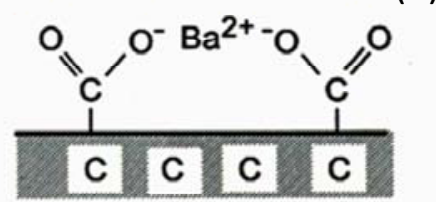

Fig. 5. Productivity of $\mathrm{H}^{+}$and $\mathrm{Ba}^{2+}$ modified oxidized carbon to produce butyl acetate in the gas phase as a function of time at $250{ }^{\circ} \mathrm{C}(\mathrm{a})$; scheme of the $\mathrm{Ba}^{2+}$-form of oxidized carbon (b) [18]. mmol/g and their surface area can reach $24 \mathrm{~m}^{2} / \mathrm{g}$. However, according to the author [11], stable and active solid acids of this type cannot be prepared by the sulphonation amorphous glassy carbon, activated carbon or naturale graphite. Heating these carbon materials in sulphuric acid resulted with only a low density of $\mathrm{SO}_{3} \mathrm{H}$ groups $(\sim 0.05-0.15 \mathrm{mmol} / \mathrm{g})$.

From our point of view, this result indicated that the reactivity of carbon materials obtained at high temperatures (active carbon, graphite) is much lower than that of incompletely carbonized aromatic compounds. Probably, they were poorly sulphonated with sulfuric acid. However, in more recent studies $[11,14,16,41]$, the possibility of carbon sulfonation to produce a carbon-based solid acid has been also reported. Moreover, as precursors, besides the aromatic compounds for carbonization, the following sulfonation also used incompletely carbonized sugars [12,15], starch [16,17], cellulosic materials [12,15,42] and polymers $[40,43]$. The amounts of acid groups in these sulphonated materials were smaller than that of the former route $(\sim 2.5 \mathrm{mmol} / \mathrm{g})$, but despite the small surface areas of these material $\left(<2-5 \mathrm{~m}^{2} / \mathrm{q}\right)$, they demonstrated good catalytic activity in the esterification of acetic acid with ethanol, hydration, dehydratation, hydrolysis of cellulose and cellobiose (373 $\mathrm{K})$, and exhibited much higher catalytic activities for transesterification (biodiesel production) and hydration than conventional inorganic solid acid catalysts $[15,44]$.

As a result of an incomplete pyrolysis of these carbohydrates (sucrose, starch, cellulose) and their sulphonating with concentrated sulfuric acid at a relatively low temperature, an amorphous carbon material with graphene sheets bearing $-\mathrm{SO}_{3} \mathrm{H},-\mathrm{COOH}$ and phenolic $-\mathrm{OH}$ groups is formed. Importantly, the catalytic activity of the materials is largely dependent on the carbonization temperature of the starting organic materials [13]. This amorphous carbon bearing acidic groups can incorporate large amounts of hydrophilic molecules, including water, into the carbon bulk. This incorporation provides good access during reactions in solution to the $\mathrm{SO}_{3} \mathrm{H}$ groups, which leads to good catalytic performance despite the small surface area of the material $\left(<2 \mathrm{~m}^{2} / \mathrm{q}\right)$.

An early study of these carbon solid acids is ref. [12], where the authors used pyrolyzed sucrose for a sulfonation process and showed its high catalytic activity in the esterification of fatty acids, which is one of the reactions that underlies the production of biodiesel.

In our study [16], we used starch-derived mesoporous materials Starbon-type [17], with hydrophilic-hydrophobic properties that can be easily controlled by the degree of carbonization (from 200 to $700{ }^{\circ} \mathrm{C}$ ). After sulphonation with concentrated $\mathrm{H}_{2} \mathrm{SO}_{4}$ ( $4 \mathrm{~h}$ at $80{ }^{\circ} \mathrm{C}$ ), samples were tested in the catalytic reaction of the esterification of succinic acid (SA). Succinic acid was used by us to study for the reason that it is a bio-platform molecule, which can be transformed into new families of useful chemicals pharmaceuticals, plant growth stimulants, feed additives, green solvents, surfactants and others. Currently, SA is predominantly produced petrochemically. Nevertheless, now SA, among several platform chemicals, can be produced from crops by fermentation with specialized bacteria [45], hence fitting in the paradigm of the biorefinery. 
Our studies showed that sulphonated Strabon in the production of the mono/di-esters of ethyl alcohol is a very active and selective catalyst. Most interesting is the fact that the catalytic process is realized even in aqueous ethanol (reaction composition as follows: $1 \mathrm{mmol} \mathrm{SA}, 30 \mathrm{mmol}$ EtOH and 50 mmol water, at $80^{\circ} \mathrm{C}$ ). Water has been reported to decrease the esterification reaction rate. Here it is interesting to compare the homogeneous process with sulfuric acid and the heterogeneous process based on our sulphonated carbonaceous materials. Sulfuric acid provides a very fast rate of conversion of the acid, but its catalytic activity is strongly inhibited by water (losing up to $90 \%$ activity with increasing water concentration). Most likely, the total hydrophilic/hydrophobic zone ratio on the carbonaceous surface created the more favorable conditions for more production of hydrophobic esters, which allowed us to obtain SA conversion to esters in amounts higher than 95\%. The efficient usage of sulphonated carbon for catalytic transformations in aqueous solutions was also discussed in $[40,43]$.

To estimate the mobility of the proton in the sulphonated carbon in our work [40], potentiometric titration curves of pyrolyzed apricot stones under $\mathrm{N}_{2}$ at $500{ }^{\circ} \mathrm{C}$ were obtained, as well as that of a spherical granulated porous styrene-divinylbenzene copolymer, sulphonated $\mathrm{H}_{2} \mathrm{SO}_{4}$ concentrated at $180{ }^{\circ} \mathrm{C}(2 \mathrm{~h})$. As seen from the curve shapes in Fig. 6, the acidity of the samples after sulfonation increased sharply. Even at $\mathrm{pH}=1.5-2$, the sorption of $\mathrm{Na}^{+}$cations was observed, which indicated the presence of appreciable amounts of groups with highly mobile protons in the surface layer $\left(\mathrm{p} K_{\mathrm{a}} \sim 1-1.5\right)$.

The catalytic activity of the starting and sulfated materials used in the hydrothermal mode $\left(140-160{ }^{\circ} \mathrm{C}\right)$ were studied using rapeseed oil transesterification (TE) with dry methanol, then methanol with the addition of water, and finally, technical ethanol containing 4\%-6\% water. The fruit stone and polymer-derived sulfonated carbon efficiently catalyzed not only the reaction with dry methanol, but also with wet alcohols at $140-160{ }^{\circ} \mathrm{C}$, i.e., under hydrothermal conditions.

At the same time, very high conversions (92\%-100\%) in the first cycle were achieved, although by the third cycle the catalyst activity was reduced to $40 \%-60 \%$ of the initial conversion.

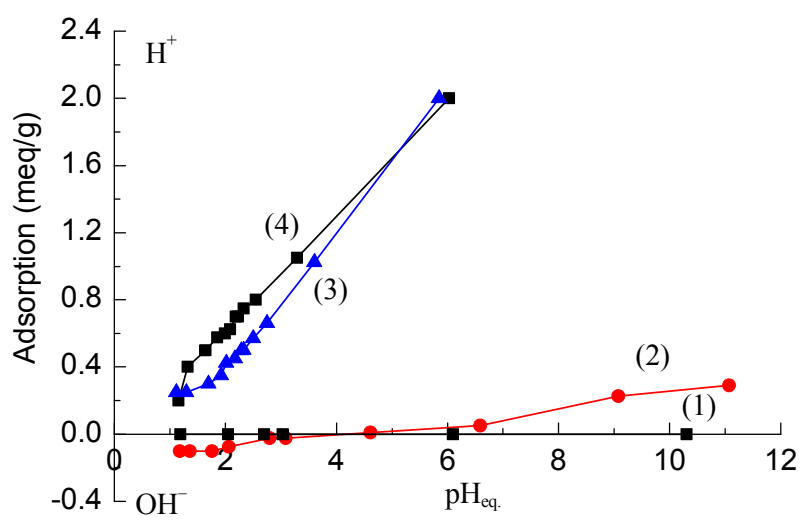

Fig. 6. Potentiometric titration curves of the samples: original ( $(1)$ and (2)) and sulphated ((3) and (4)) incompletely pyrolyzed $\left(500{ }^{\circ} \mathrm{C}\right)$ apricot stones ((1) and (3)) and spherically granulated porous styrendivinilbenzene copolymer ((2) and (4)).
Most likely this was due to that in the hydrothermal mode, there was a process of gradual reduction of sulfonic groups on the surface, as in almost all the experiments $\mathrm{SO}_{2}$ were generated.

Therefore, not only in the case of succinic acid esterification [16], but also in rapeseed oil transesterification with alcohols, it was well established that strongly acidic (sulphonated) carbon-based materials have their ability to catalyze protontransfer processes inhibited by the presence even of a small amount of water in the reaction medium. Undoubtedly this was due to the presence of hydrophobic zones in the surface layer of these catalysts, and that their interaction with the components of the reaction system facilitated the formation of a catalytic (more hydrophobic than the initial reagents) intermediate complex responsible for the formation of final reaction products [16].

To conclude this section, the results obtained in ref. [14] should be mentioned, which demonstrated the high efficiency of sulphonated carbon in the reaction of glycerol acetylation with acetic acid. Active carbon was sulphonated by $\mathrm{H}_{2} \mathrm{SO}_{4}$ (concentrated) at $85^{\circ} \mathrm{C}(4 \mathrm{~h})$. The acylation process was carried out at $120^{\circ} \mathrm{C}(3 \mathrm{~h})$. In this method, the catalyst did not lose its activity (in a 4-cycle experiment). Comparing this result with the data of our work [40] in which the catalytic process was carried out at $140-160^{\circ} \mathrm{C}$, it can be assumed that the reduction of sulfo groups began at temperatures above $120{ }^{\circ} \mathrm{C}$, i.e. the catalyst (sulphated carbon) was stable at this temperature and below.

Also interesting are the studies in which as the starting material used cellulose and a waste of the paper making industry lignosulfonete $[44,46]$, for the synthesis of the sulphonated products of its pyrolysis, i.e., the solid acid catalysts $[13,15,42,44]$. The authors [44] were the first to demonstrate the effectiveness of these sulphonated activated carbon catalysts in the hydrolysis of cellulose into glucose. Research on this topic is mainly on the chemical transformation of biomass into bio-based platform chemicals to solve biorefinery problemsglucose, ethanol, hydrocarbon, fructose, acetic acid, 5-hydroxymethylfurfural (HMF) and biodiesel production. Usually, sulphuric acid is used for cellulose catalytic hydrolysis. However, an opportunity for the efficient conversion of cellulose to cellulose-derived carbon sulphonated material revealed in $[13,15,42,44,46]$ can open prospects for creating an economically and technologically acceptable manufacturing process.

In the studies in ref. [47], the process of obtaining the carbon material bearing $\mathrm{SO}_{3} \mathrm{H}$ groups and the catalytic transformation of pure microcrystalline cellulose on this catalyst was investigated more thoroughly. The catalyst synthesis was carried out by heating the microcrystalline cellulose powder $5 \mathrm{~h}$ at $723 \mathrm{~K}$ under $\mathrm{N}_{2}$ flow and then treating with fuming sulfuric acid at $353 \mathrm{~K}$ also under $\mathrm{N}_{2}$. The hydrolysis of cellulose into water soluble $\beta-1,4$ glucan and glucose using the synthesized catalyst was realized at $373 \mathrm{~K}$. It is interested that crystalline pure cellulose is not hydrolyzed by conventional strong acid catalysts such as niobic acid, H-mordenite, Nafion and Amberlist-15, whereas amorphous carbon bearing $-\mathrm{SO}_{3} \mathrm{H},-\mathrm{COOH}$ and $-\mathrm{OH}$ groups is an efficient catalyst for the reaction. The catalyst 
synthesized from eucalyptus wood also showed high activity.

Glucose and fructose obtained by cellulose hydrolysis, after dehydration on acid catalysts can be converted into 5-hydroxymethylfurfural, which is a very important and versatile intermediate that can be transformed into a wide variety of high performance fuels such as 2,5-dimethylfuran, 5-ethoxymethylfurfuran, levulinic acid, ethyl levulinate, linear alkanes and others $[42,43,48]$. The investigation [43] showed the high catalytic activity of sulphonated carbonaceous materials in this reaction, including samples synthesized from metallorganic compounds, as well as from lignosulphonate. The reaction medium tested were water, organic solvents, and even an ionic liquid [46].

The precursor for the carbonaceous material used in ref. [41] was polydivinylbenzene, with further sulfonation with $\mathrm{H}_{2} \mathrm{SO}_{4}$ concentrated at $250{ }^{\circ} \mathrm{C}$, i.e. by a one-pot treatment. The final product had the following parameters for its porous structure: $S_{\mathrm{sp}}=75 \mathrm{~m}^{2} / \mathrm{g}$ and pore size $=15 \mathrm{~nm}$. The catalytic test in the dehydration process of fructose to HMF showed that the catalyst exhibited both high activity and good recyclability. However, conducting the process at $110{ }^{\circ} \mathrm{C}$ in aqueous solution led to a very low yield of HMF (2.5\%), and only the catalytic conversion in DMSO solution reached $64.5 \%$ yield.

\section{Acidic catalysts based on phosphated carbonaceous materials}

The increased interest in the possibility of creating more efficient proton transfer catalysts (than sulphonated carbonaceous materials) has stimulated attempts for their synthesis by phosphating of carbon precursors (natural and synthetic polymers [7-10]). There is a well known method of carbon activation by the heat treatment of a mixture contained the carbonaceous materials and phosphoric acid [3]. Unfortunately, the chemical nature of this process is not sufficiently studied. However, it is probable that after the high temperature treatment the surface, the activated carbon would contain grafted onto its carbon surface $\mathrm{P}-\mathrm{OH}$ or $(\equiv \mathrm{P}-\mathrm{O}-\mathrm{P} \equiv)_{x}-(\mathrm{OH})_{y}$ groups. Because elemental phosphorus is produced by the calcination of apatite with carbon in the absence of air, these groups can be considered as intermediate states, realized in the system during elemental phosphorus formation. The authors [7] showed that as a result of the heat treatment of a mixture contained phosphoric acid and carbonaceous row materials (activation by phosphoric acid), activated carbon with a phosphorus content of $7.2 \%-9.5 \%$ was formed. In the case of the calcination of activated carbon at $800{ }^{\circ} \mathrm{C}$ with the same acid, only $3.5 \%$ of phosphorus was binded with the carbon matrix. The pronounced acidity of phosphate groups grafted onto the surface, and their high chemical stability even in alkaline solutions and acids was also established.

An example of ethyl tertiary-butyl ether synthesis from isobutylene and ethanol showed that the phosphorus carbon is an active acidic catalyst [9]. Finally, the authors [10] synthesized mesoporous phosphorylated carbon by following a "one-pot" procedure by heating at $80{ }^{\circ} \mathrm{C}$ and subsequent calcination at $850{ }^{\circ} \mathrm{C}$ of a mixture contained $\mathrm{H}_{3} \mathrm{PO}_{4}$ and $\mathrm{HNO}_{3}$ with resorcinol, formaldehyde and non-ionic copolymer Pluronic F127. The obtained carbon catalyst was a strong solid acid and exhibited good activity for the degydration of fructose to HMF even in water. These phosphorylated carbon are able to reduce byproducts (levulinic acid and humines) yielding selectivity to HMF up to $70 \%$ versus only $36 \%$ with sulphonated carbon.

\section{Conclusions}

Solid acid catalysts have many advantages over liquid Bronsted and Lewis acid catalysts in liquid phase processes. These catalysts conform to the concept of a "green" approach to chemical processes, and are actively researched. This is because they are easily separated from liquid products, and are noncorrosive, have a longer catalyst life, have fewer disposal problems, and have recyclability and the possibility to be designed to give high activity and selectivity. Although the author [49] back in 1999 reported that nearly 120 industrial processes out of 130 are catalyzed by solid acid, an unrecyclable homogeneous acid catalyst at the present time is still used with more than 15 million tons of $\mathrm{H}_{2} \mathrm{SO}_{4}$ each year [11]. Therefore, studies on effective solid acid catalysts and the development of new advanced technologies based on them are fully justified. As discussed in this review, developing effective acid catalysts based on activated carbon and pyrolyzed carbonaceous materials deserves special attention. Besides cost effectiveness, carbonaceous solid acids have the unique ability of keeping its catalytic activity not only in organic solutions, but also in aqueous solutions. They can be used in the implementation of practical important processes of etherification, transesterification (biodiesel) and dehydration, which proceeded with the release of water. This is probably due to the surface hydrophilic/hydrophobic properties of these catalysts.

In the review, we pointed out that deeply oxidized activated carbons are highly effective catalysts in proton transfer reactions. They approach the strength of acidity of sulphoresins. Using computation (ab initio method), an interpretation of the causes of the increased acidity of the carboxylic groups of highly oxidized carbon was proposed. Also discussed was an interesting phenomenon of the high catalytic activity of cationsubstituted (saline) modification of oxidized carbon in the gaseous and liquid phases of the processes. Finally, recent studies aimed at the development of an amorphous carbon acid catalyst consisting of flexible polycyclic carbon sheets with $-\mathrm{SO}_{3} \mathrm{H}$, - $\mathrm{COOH}$ and phenolic type $\mathrm{OH}$-groups in a three dimensional graphene-type network were analyzed. New catalysts can be readily prepared by the partial carbonization of some organic compounds including polymers and, most interesting, available natural compounds such as sugar, starch, cellulose, followed by the sulfonation and phosphatation of the resulting carbonaceous materials. These low cost and environmentally friendly catalysts were successfully tested for potential application in biodiesel synthesis in the environmentally benign saccharification (hydrolysis) of cellulose and catalytic conversion of carbohydrates (glucose and fructose) into 5-hydroxymethylfurfural, which is a versatile and key intermediate in the biofuel, chemistry and petroleum industry. 


\section{Graphical Abstract}

Chin. J. Catal., 2014, 35: 815-823 doi: 10.1016/S1872-2067(14)60147-9

\section{Proton catalysis with active carbons and partially pyrolyzed carbonaceous materials}

V. V. Strelko*, S. S. Stavitskaya, Yu. I. Gorlov

Institute for Sorption and Problems of Endoecology of NAS of

Ukraine, Ukraine

Protonogenic functionality of deeply oxidized and phosphated active carbons, as a pyrolized sulphated organic materials determines their catalytic activity in acid-base reactions. These materials have well prospective in the field biorefining namely in bio-mass processing.

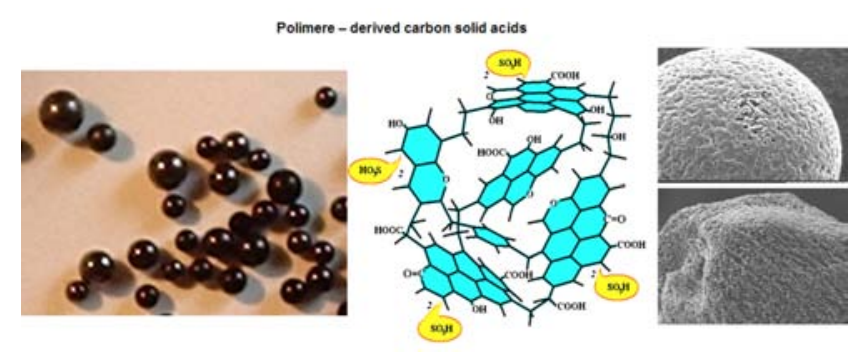

Carbon, 1998, 36: 899

[24] Grunewald G C, Drago R S. J Am Chem Soc, 1991, 113: 1636

[25] Szymanski G S, Rychlicki G, Terzyk A P. Carbon, 1994, 32: 265

[26] Carrasco-Marin F, Mueden A, Moreno-Castilla C. J Phys Chem B, 1998, 102: 9239

[27] Zawadzki J, Wisniewski M, Weber J, Heintz O, Azambre B. Carbon, 2001, 39: 187

[28] Clark J H. Acc Chem Res, 2002, 35: 791

[29] Strelko V V, Stavitskaya S S, Strelko V V Jr, Streat M. Theor Experim Chem, 1998, 34(1): 27

[30] Gregor H P, Hamilton M J, Becher J, Bernstein F. J Phys Chem, 1955, 59: 874

[31] Contescu A, Contescu C, Putyera K, Schwarz J A. Carbon, 1997, 35 : 83

[32] Lahaye J, Nanse G, Bagreev A, Sterlko V. Carbon, 1999, 37: 585

[33] Strelko V V.J Energy Chem, 2013, 22: 174

[34] Strelko V V ed. Selective Sorption and Catalysis on Active Carbon and Inorganic Ion Exangers (Russ). Kiev: Naukova dumka, 2008. 304

[35] Dunning T H Jr.J Chem Phys, 1989, 90: 1007

[36] Stavitskaya S S, Davydov V I, Korvyakov S G. Ukrain Chem J, 1992, 58: 165

[37] Korvyakov S G, Stavitskaya S S, Davydov V I. Ukrain Chem J, 1993, 59: 926

[38] Ryabov S I, Shostka G D, Lukichev B G, Strelko V V, Spiridonov V N, Kartel N T, Scherbitsky A B. Intern Urology Nephrology, 1984, 16: 345

[39] Strelko V V, Korovin Yu F, Kartel N T, Shcherbitskii A B. Russ J Appl Chem, 1984, 57: 1225

[40] Fedorishin A S, Strelko V V, Stavitskaya S S, Yakovlev V I, Tsyba N N, Mil'grandt V G. Russ J Appl Chem, 2010, 83: 281

[41] Onda A, Ochi T, Yanagisava K. Top Catal, 2009, 52: 801

[42] Qi X H, Guo H X, Li L Y, Smith R L Jr. ChemSucChem, 2012, 5: 2215

[43] Wand L, Zang J, Zhu L F, Meng X J, Xiao F S. J Energ Chem, 2013, 22 : 241

[44] Onda A, Ochi T, Yanagisawa K. Creen Chem, 2008, 10: 1033

[45] Koutinas A A, Wang R, Webb C. Biotechnol Bioeng, 2004, 85: 524

[46] Lee D. Molecules, 2013, 18: 8168

[47] Suganuma S, Nakajima K, Kinato M, Yamaguchi D, Kato H, Hayashi S, Hara M. J Am Chem Soc, 2008, 130: 12787

[48] Wang J J, Xu W J, Ren J W, Lin X H, Lu G Z, Wang Y Q. Green Chem, 2011, 13: 2678

[49] Tanabe K, Hölderich W F. Appl Catal A, 1999, 181: 399 